\title{
AUTOMATION ENGINEERING SERVICE FOR CORN STEEPING AND WET MILLING PROCESSES, IN FACTORY OF GLUCOSE AND CORN DERIVATIVES (GYDEMA): CIENFUEGOS, CUBA
}

\author{
Leyanis Albo Valladares ${ }^{1}$ and Oscar Hernández Baute ${ }^{2}$
}

${ }^{1,2}$ Integral Automation Enterprise - CEDAI. Cienfuegos, Cuba.

Email: 1eyanis@cedai.com.cu, leyanis.albo@gmail.com

Received: Mar 04th, 2020

Accepted: Apr 22 ${ }^{\text {th }}, 2020$

Published: April 30th, 2020

Copyright (02016 by authors and Galileo Institute of Technology and Education of the Amazon (ITEGAM).

This work is licensed under the Creative Commons Attribution International License (CC BY 4.0).

https://creativecommons.org/licen ses/by/4.0/

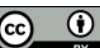

Open Actese

\begin{abstract}
The factory of glucose and corn derivatives of Cienfuegos is one of the most important factories of this city's industrial pole. As part of the modernization of processes on this factory, an automation engineering service was carried out by the CEDAI Enterprise of Cienfuegos. The main goal of this service was to implement a control system that will optimize steeping and wet milling processes, improve the process operation, increase the productive capacity of these areas as well as the product quality. To do so, many tasks were executed, it was necessary to replace the obsolete equipment, as well as pneumatic equipment, and the incorporation of new technologies for process control. Likewise, the development and implementation of a SCADA for steeping process. On the other hand, the wet milling process was provided with a modern MCC, equipped with advanced technology to this end, which includes a PROFINET network for motor control and using SIEMENS technology. Additionally, an HMI based SCADA was implemented to control the wet milling process. With the final application of this service, centralized control of pumps and motors of these processes was achieved, as well as supervise the status of the corresponding equipment and continuously monitoring the process variables through simple interfaces, easy to use and interact. Thus far, the developed control systems has been operating for more than two years and its implementation was a step forward for the technological upgrade of the factory, improving consumption rates, saving energy and increasing the production rates, as well as the quality of the product.
\end{abstract}

Keywords: Industrial Automation, Control System, SCADA, Corn Wet Milling.

\section{INTRODUCTION}

The factory of glucose and corn derivatives (GyDeMa) is located on Cienfuegos province, in Cuba. It is intended to obtain corn starch and glucose, which are essential to manufacture a lot of either alimentary or cosmetic products on the region.

This factory has many working years and a remarkable technological slowdown, because of the lack of an adequate maintenance plan for the existent equipment and a nonexistent investment plan on new technologies to improve the process.

This industrial process is divided into many areas such as: cleaning, weighing, steeping, wet milling, fiber washing, pressing and drying, just to mention a few. This paper focuses on steeping and wet milling processes.
In order to achieve higher production levels and increase the quality of the final product, guaranteeing the technological update of the factory and facilitating the operation of the process, the Integral Automation Enterprise (CEDAI) of Cienfuegos carries out an automation engineering service.

The given service had three fundamental stages, such as replacing obsolete and defective equipment; to incorporate new equipment with modern technologies for process control (sensors for measuring process variables and equipment status, modern Motor Control Center (MCC) with intelligent devices for motor protection and control; and finally, the implementation of Supervisory Control and Data Acquisition (SCADA) for process control. 


\section{I.1 PROBLEM SITUATION}

The control equipment in both process areas was truly obsolete and the lack of an automated process brought with it many consequences like inefficiency.

On both areas, there was no control over motors and pumps, command and signaling units as well as protection and control devices were defective and damaged. As described, the milling process is basically constituted by the control of motors and pumps, so this problem should be resolved with priority.

In contrast, specifically on Steeping Area, pneumatic sanitary valves and the equipment to control them was obsolete and not functional; process temperatures were not taken continuously and correctly, so the steeping process tended to fail or get unwanted results.

To solve these problems and guaranteeing the technological update of the plant, on each process different automation methods were used, but always using the Programmable Logic Controller (PLC) and Human Machine Interface (HMI) / SCADA architecture for control systems.

\section{DEVELOPMENT}

Steeping and wet milling of corn are simple processes, however, the results obtained at the GyDeMa factory were not adequate due to the technological obsolescence of the equipment.

For a better understanding of the work performed, a description of the technological process must be made.

\section{II.1 DESCRIPTION OF CORN STEEPING AND WET MILLING TECHNOLOGICAL PROCESSES}

Once the corn is received at the factory by trucks, a cleaning process is performed using a cleaning system with dedusters, vibration screens, elevators and sieves, in order to remove cobs, dust and foreign materials. Then, it is weighted and conveyed to the predefined SS tank for steeping. The quantity of corn to be steeped is controlled by the weighing system (approximately 30 Tm per tank).

The SS steeping tank is previously prepared for the process. It is deeply cleaned and half filled with sulfurous acid $\left(\mathrm{H}_{2} \mathrm{SO}_{3}\right)$. This substance is the result of irrigating water over the fumes of burning sulfur (S), which is frequently employed as food preservative and fungicide, preventing excessive bacterial growth. [1]

When the predefined amount of corn is achieved, the SS tank is fulfilled then on a mixture of sulfurous acid and fresh water, to completely cover up the grains of corn. At this point, the SS tank is ready to start the steeping process, where the corn soaks at 50-52 degrees Celsius, on a recirculation cycle inside the SS tank. To do so, motors, pumps, temperature sensors and pneumatic sanitary valves are used.

The steep process takes over 40-60 hours, depending of corn, and at this point the corn has swelled and softened, ready for wet milling. Then, the SS steeping tank is drained out and the corn is carried to the Wet Milling Area. [2]

The wet milling process has several sub-stages. In the corn wet milling process, the corn kernel is separated into its component parts, and those parts are then further subdivided and refined. [3]

In this process the mechanical separation of the corn kernel components (fibers, germ and starch) occur. Initially, the corn passes through a stone separator and then added into the first mill, where water is poured to moisten the milling process.
The three mills employed on the complete process are cog wheeled mills; the first one, particularly, performs a coarsely ground, guaranteeing the braking of the grain without damaging the germ. It is necessary to not break the germ, since it has a high content of oil [3] and would cause disturbances in the following stages of the process.

Taking advantage of the properties of the germ, which floats over the slurry obtained during the milling process, it is separated using centripetal force on stainless steel vats with agitator. This process is repeated for a second time, but using fine mills, obtaining fibers and a suspension of starch.

The germ, fibers and the suspension of starch are independently washed using rotary screens to catch any residual starch [2].

Once the milling process has finished, the suspension of starch is submitted to other processes like starch-gluten separation, and starch drying, in order to obtain starch as final product.

\section{II.2 AUTOMATION FOR STEEPING AND WET MILLING PROCESSES}

\section{II.2.1 Programmable Logic Controller (PLC)}

A Programmable Logic Controller (PLC), also referred to as programmable controller, is the name given to a type of computer commonly used in commercial and industrial control applications. PLCs monitor inputs and other variable values, make decisions based on a stored program, and control outputs to automate a process or machine. [4]

In accordance with [5], the controller governs the output signals according to the program control logic previously stored in memory on the central processing unit (CPU) of the PLC, based on the state of the input signals. This program is inserted into the PLC through the programming unit, which also allows additional functions such as program debugging, simulation, monitoring, PLC control and more.

\section{II.2.2 Human Machine Interface (HMI)}

Human Machine Interface or HMI are devices used in industry to control and monitor machines. They may include information like temperature, pressure, process steps, and material counts. [6]

HMIs use special software so engineers can program them correctly. The software allows the engineer to design what the operator will actually see on the screen, what they can monitor on the screen, and how the operator can manipulate the machine. Engineers can program an HMI to perform almost any function that can be controlled or information that can be monitored by a PLC. HMIs and PLCs work together to monitor and control the machine using an industrial network. [6].

\section{II.2.3 Automation of steeping process}

In this area, the automation engineering service was executed using the existing equipment in CEDAI warehouse. So two controllers were installed, given the limited number of expansion modules they support and the huge amount of signals to treat. One controller manages motors, pumps and pneumatic sanitary valves, and a second controller manages process temperature signals.

There was developed and implemented a SCADA, to run in the control station, using a high performance personal computer (PC). 
For motors and pumps, all command and signaling units, as well as protection and control devices were replaced with new equipment and also, integrated to the new control system with control relays. Likewise, two temperature sensors were installed per tank, one at the top, right on the feeding water pipe of the SS tank, and other at the bottom. Pneumatic sanitary valves were replaced for new ones with an indicator unit for positioning; for control pneumatic solenoid valves were installed, converting electrical signals into pneumatic functions.

Both controllers are connected to a PPI/MPI network and share information with the SCADA. The rest of the signals are independently wired to controllers; no fieldbus was used, as presented on Figure 1.

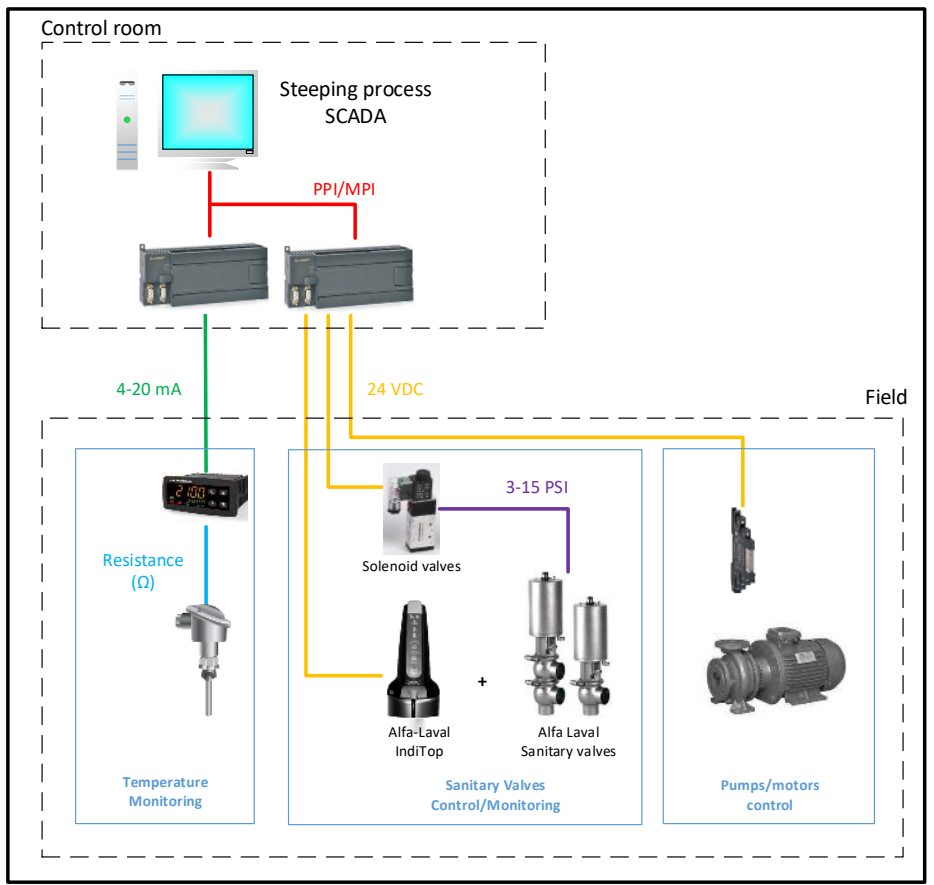

Figure 1: Control system for steeping process.

Source: Authors, (2020).

\section{II.2.4 Automation of wet milling process}

For wet milling process automation, a new control system based on SIEMENS technology and PROFINET communication was developed and implemented, as exposed on Figure 2.

To this end, a complete substitution of the conventional Motor Control Center (MCC) and the obsolete control system was performed. The new MCCs, were equipped with modern switching and short-circuit protection mechanisms, as well as a power monitoring system with SENTRON components. Also, to control motors and pumps, devices like: SIRIUS Motor Management and Control Device (SIMOCODE PRO) and SIRIUS 3RW44 Soft Starters were installed. According to [7], SIMOCODE pro links the higher-level automation system and the motor feeder intelligently.

The SIRIUS 3RW44 Soft Starter, on the other hand, is an electronic motor control device for optimized starting and stopping of 3-phase asynchronous motors. [8].

For process control, SIEMENS S7-1200 controllers were installed. Because of their compact design, flexible configuration, and powerful instruction set, these controllers provide the flexibility and power to control a wide variety of devices on a wide variety of applications. [9].

Additionally, a SCADA based on HMI was implemented on a SIMATIC HMI TP1500 Basic PN panel, in order to actuate process motors and pumps.

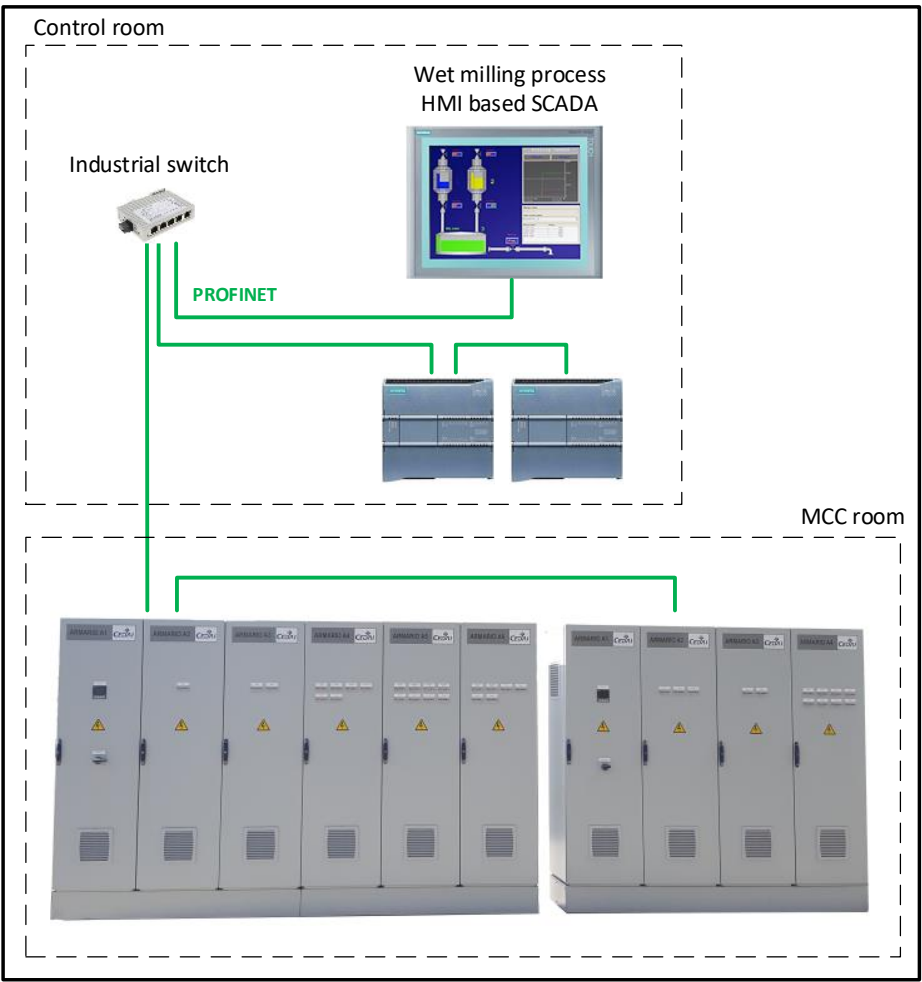

Figure 2: Control system for wet milling process. Source: Authors, (2020).

Besides, Static Var Compensators (SVC) are devices that can quickly and reliably control line voltages [10], for this purpose, they were incorporated to the main power supply network.

\section{II.3 AUTOMATION TECHNOLOGY}

\section{II.3.1 Control system for steeping process}

On Steeping Area, UniMAT controllers - CPU 226 - were installed with expansion modules of the same company (Figure 3). UniMAT CPU 226 is manufactured in China and it's similar to SIEMENS S7-200 controller.

Also, guarantees signal processing, safe and correct operation of all the programmed sequences and logic algorithms. As well, it has the following features:

- CPU 226 DC/DC/DC, power 24 VDC, program memory size of $24 \mathrm{~KB}$ and $10 \mathrm{~KB}$ of data memory, 24 digital inputs, 16 digital outputs, 2 PPI/MPI ports and up to seven expansion modules. [11]

- UniMAT expansion modules used: EM223 - 32 digital inputs module, EM222 - 32 digital outputs module, EM231 - 8 analog inputs module.

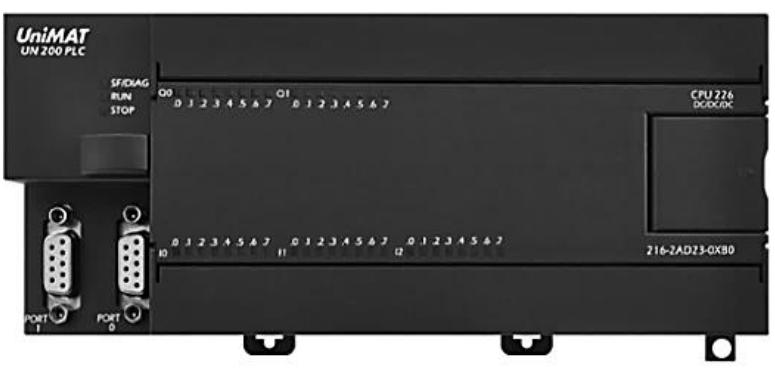

Figure 3: UniMat CPU 226 DC/DC/DC. Source: [11]. 
Besides, control system was also integrated by the following elements:

- TB11-6 (Figure 4). RTDs from Thermibel manufacturer, SC-TB series screw-in probes with sheathed, non-replaceable sensing element and DIN B connection head, with Pt100 sensing element, sliding connector and three wires for signal output.

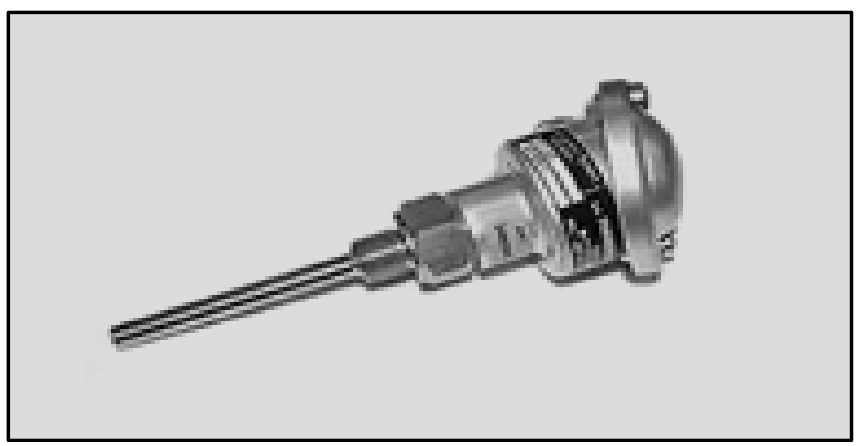

Figure 4: TB11-6 Thermibel RTD.

Source: Authors, (2020).

- Temperature controller programmer KR3 (Figure 5), from ASCON TECNOLOGIC manufacturer. These devices were used as transducers, receiving the resistance signal from the RTDs, screening the temperature value and transmitting to UniMat controllers over 4-20mA signal.

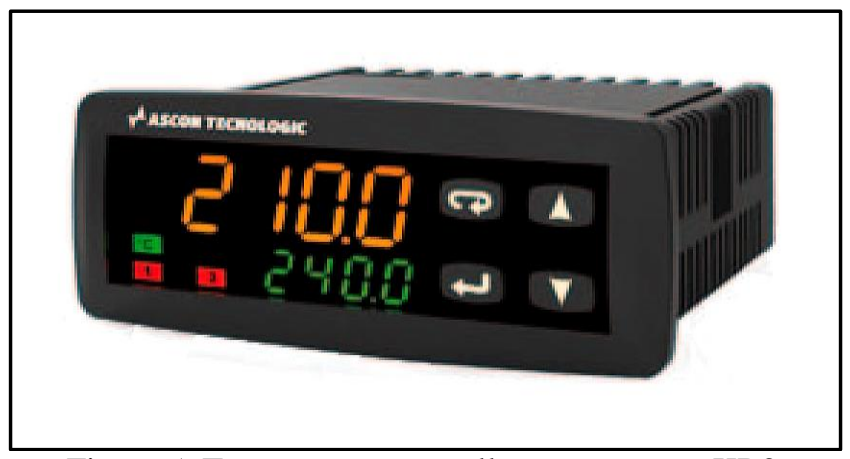

Figure 5: Temperature controller programmer KR3.

Source: [13].

- IndiTop (Figure 6), is an indicator unit for sanitary valves positioning from Alfa Laval manufacturer. IndiTop is designed to be a part of the PLC's Input/Output (I/O) system, and it's attached to sanitary valves. Positioning is firstly programed on Setpoint 1 or 2, and then matched to controller's logic [13].

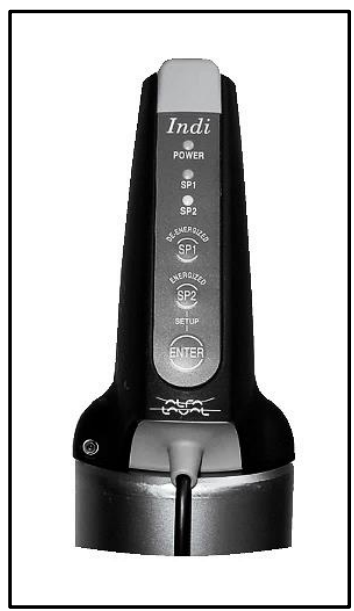

Figure 6: Alfa Laval IndiTop.

Source: [13].

\section{II.3.2 Control system for wet milling process}

The devices that compose the control system have the following features:

- SIMATIC S7-1200, CPU 1214C AC/DC/relay (Figure 7): it's a compact CPU with 1 PROFINET port and an onboard inputs/outputs distribution: 14 digital inputs (24 VDC), 10 digital outputs (relay) and 2 analog inputs (0-10 VDC). Power supply: 85$264 \mathrm{VAC}$ and program/data memory of $100 \mathrm{~KB}$. Up to 16 connectable IO devices. Article number: 6ES7214-1BG40-0XB0 [14].

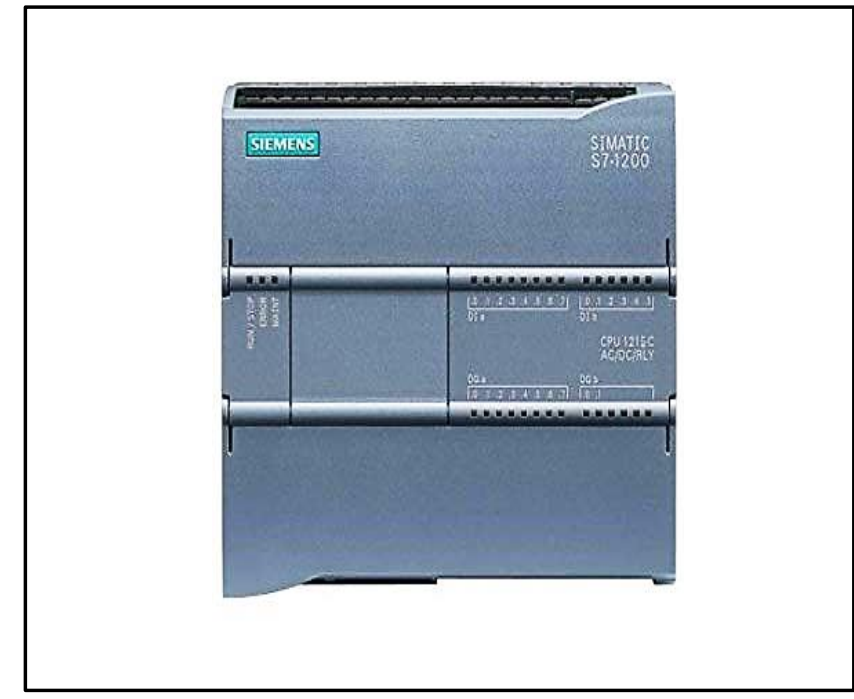

Figure 7: SIMATIC S7-1200, CPU 1214C AC/DC/relay. Source: [15].

- SIMATIC S7-1200, CPU 1215C AC/DC/relay (Figure 8): it's a compact CPU with 2 PROFINET ports and an onboard inputs/outputs distribution: 14 digital inputs (24 VDC), 10 digital outputs (relay), 2 analog inputs (0-10 VDC) and 2 analog outputs (0-20 mA). Power supply: 85-264 VAC and program/data memory of $125 \mathrm{~KB}$. Up to 16 connectable IO devices. Article number: 6ES7215-1BG40-0XB0 [16].

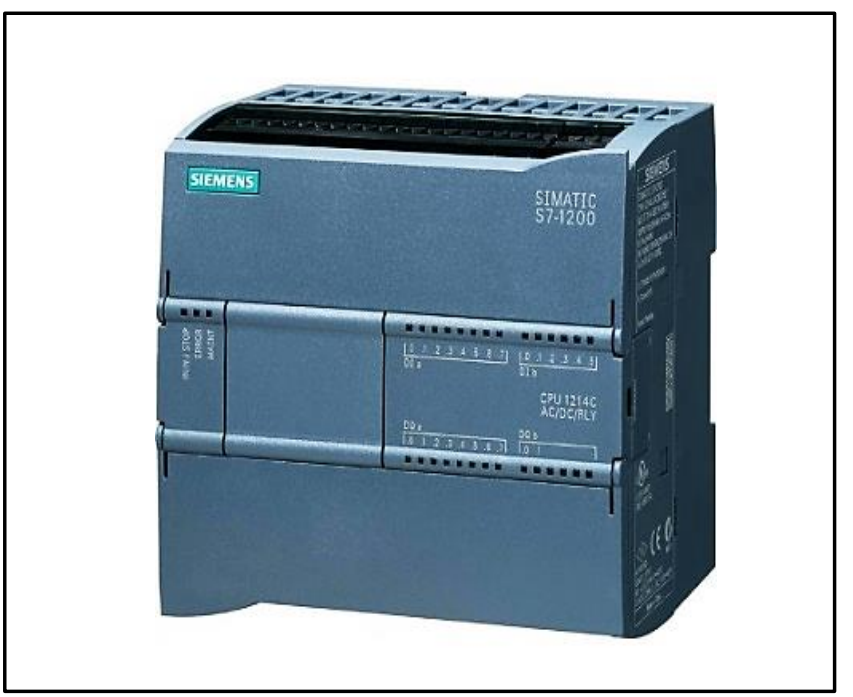

Figure 8: SIMATIC S7-1200, CPU 1215C AC/DC/relay. Source: [17].

- SIMATIC HMI TP1500 Basic PN panel (Figure 9); it has a 15 " TFT display, with touch operation and one PROFINET interface [18]. 


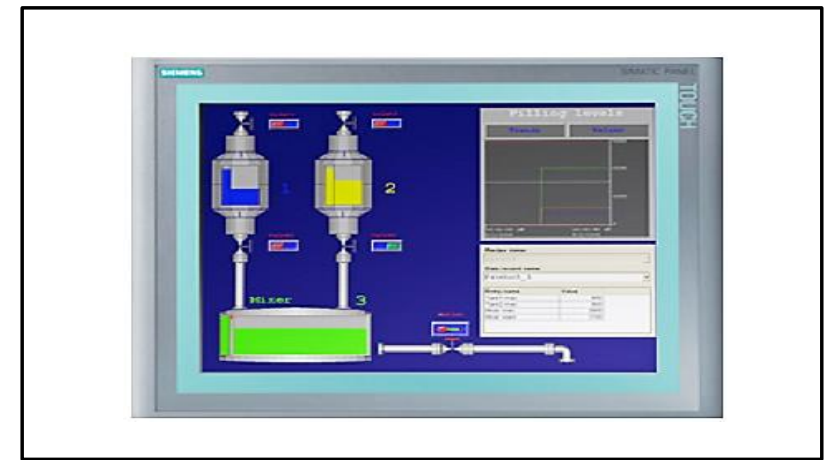

Figure 9: SIMATIC HMI TP1500 Basic color PN. Source: [18].

- SIMOCODE PRO, according to [7] is a flexible and modular motor management system for motors with constant speeds in low-voltage applications. It optimizes the link between the control system and the motor feeder, increases plant availability and allows significant savings to be made during installation, commissioning, operation and maintenance. In this case, SIMOCODE PRO V PN were installed (Figure 10), which incorporates 2 PROFINET ports.

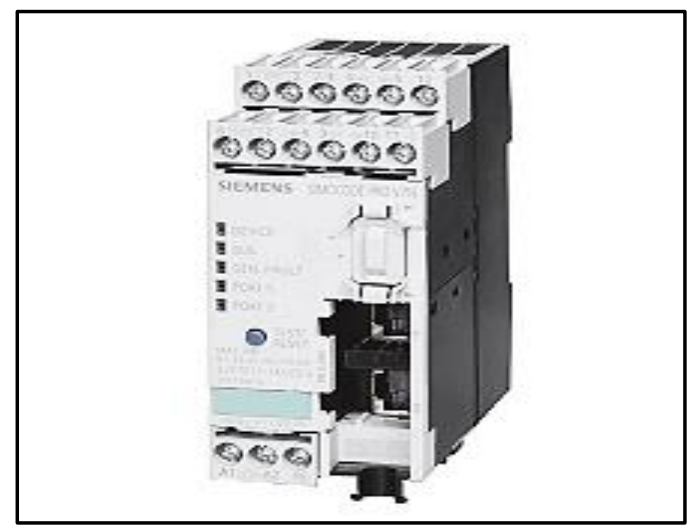

Figure 10: SIMOCODE PRO V PN. Source: [19].

- SIRIUS 3RW44 Soft Starter (Figure 11), is an alternative for star-delta starters and frequency converters; in this case, they were used on motors and pumps without speed control, where no particularly high starting torque or no startup with close to nominal current was required [20].

Their major benefits are smooth starting and stopping, uninterrupted changeover without current peaks that would stress the power supply, and their compact dimensions [20].

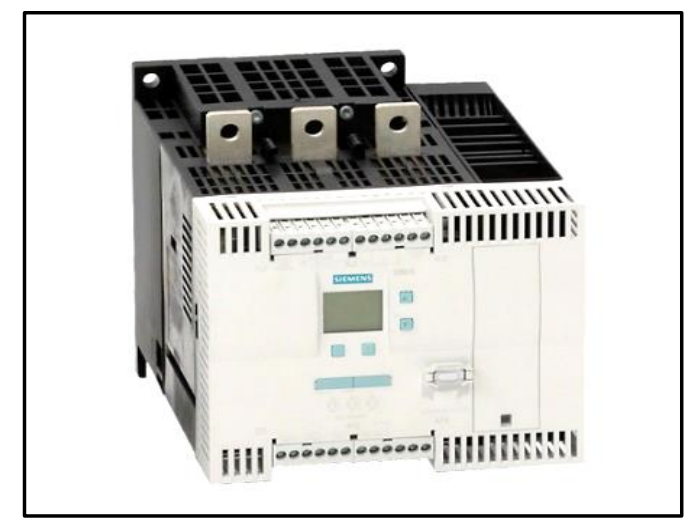

Figure 11: SIRIUS Soft Starter 3RW44. Source: [8].
- SENTRON PAC 3200 (Figure 12), it is a power monitoring device for displaying all the relevant system parameters in low-voltage power distribution [21].

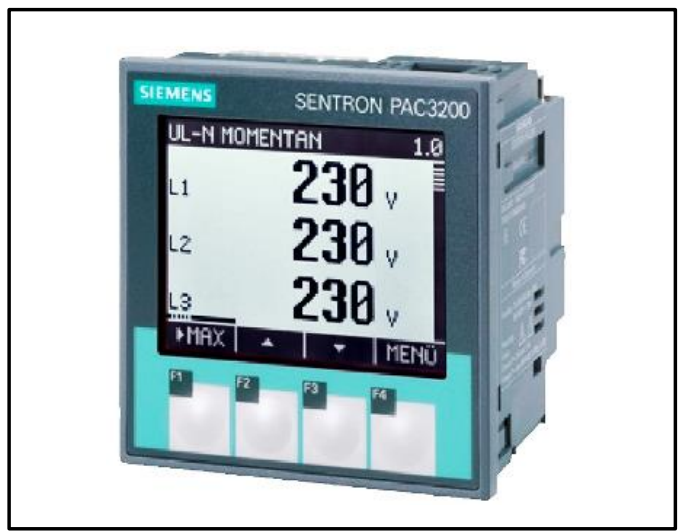

Figure 12: SENTRON PAC 3200.

Source: [22].

\section{II.4 PROGRAMMING SOFTWARES}

To program all the previously mentioned devices, many programming softwares were used:

- STEP 7 - Micro/WIN software (SIEMENS), for programming UniMat CPU 226. This programming package provides a user-friendly environment to develop, edit, and monitor the logic needed for control applications. It also offers a variety of tools and features for designing, implementing, and debugging programs for S7-200 controller's family [23].

- SIMATIC WinCC v7.0 software (SIEMENS), to develop the SCADA for the steeping process. SIMATIC WinCC is an HMI software program for the operator control and monitoring of automated processes in the machine-manufacturing and plantengineering industries. This software has high functionalities, high efficiency and it's easy-to-use [24].

- TIA Portal V14 SP1 (SIEMENS) to develop the control system programming each device on wet milling area. TIA Portal, is the Totally Integrated Automation Portal which is a complete software package that includes for example: STEP 7, WinCC and SIMOCODE ES.

STEP 7 (TIA Portal) is the engineering software to configure the SIMATIC S7-1200, S7-1500, S7-300/400 and WinAC. STEP 7 provides a user-friendly environment to develop, edit, and monitor the logic needed to control applications [25]. In this case, for programming the S7-1200 devices STEP 7 Professional edition was used, as part of TIA Portal V14 SP1.

On the other hand, and in accordance with, [25], WinCC (TIA Portal) is an engineering software for configuring SIMATIC Panels, SIMATIC Industrial PCs, and Standard PCs with visualization software. To program and configure the SIMATIC HMI TP1500 Basic color PN, WinCC Professional edition was used, as part of TIA Portal V14 SP1.

Lastly, SIMOCODE ES V14 (TIA Portal), is the central software package for the configuration, commissioning, operation, and diagnosis of SIMOCODE pro [26].

\section{RESULTS}

Once the mounting and starting up stages ended, the automation engineering service obtained satisfactory results.

For steeping process, from the implemented SCADA system, operators can have full control over the process from the control room, monitoring process temperatures, setting and 
monitoring the sanitary valves position, managing warnings and alarms and controlling motors and pumps, using control faceplates and interactive menus to shift control screens. This SCADA
(Figure 13) has a friendly graphical interface which allows comfortable interaction with the user, allowing easy operation and fast learning of the system.

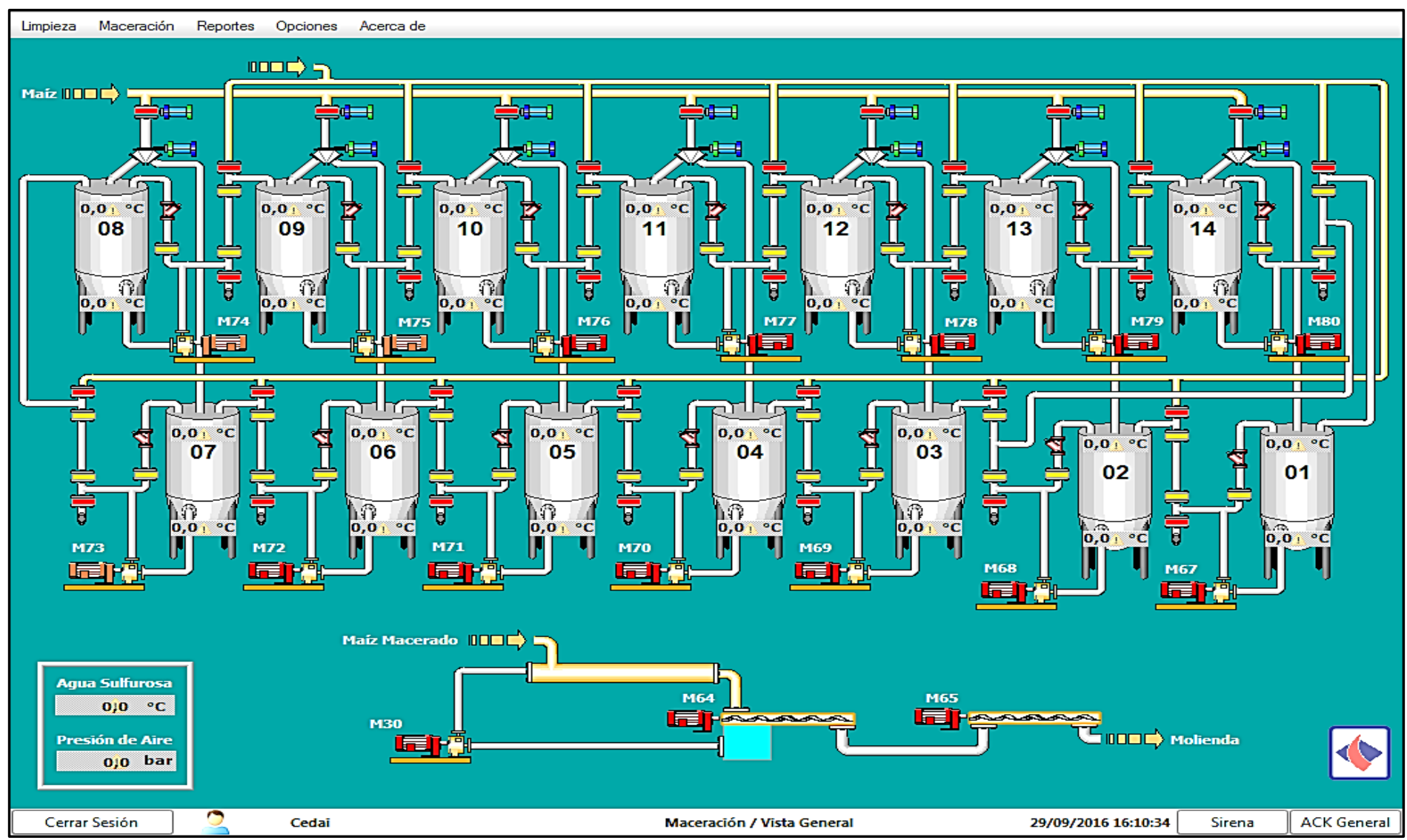

Figure 13: SCADA for seeping process.

Source: Authors, (2020).

On the other hand, for wet milling process, with the HMI based SCADA, centralized control of pumps and motors was achieved, where it is possible to manually or automatically control the process following the operation sequence through work-groups. Also, it is possible to visualize the status of the equipment (ready, failing, running, disabled, starting) and the behavior of its electrical parameters; with monitoring, management and information on the nature of warnings and alarms; all through a simple interface, easy to use and interact (Figure 14).

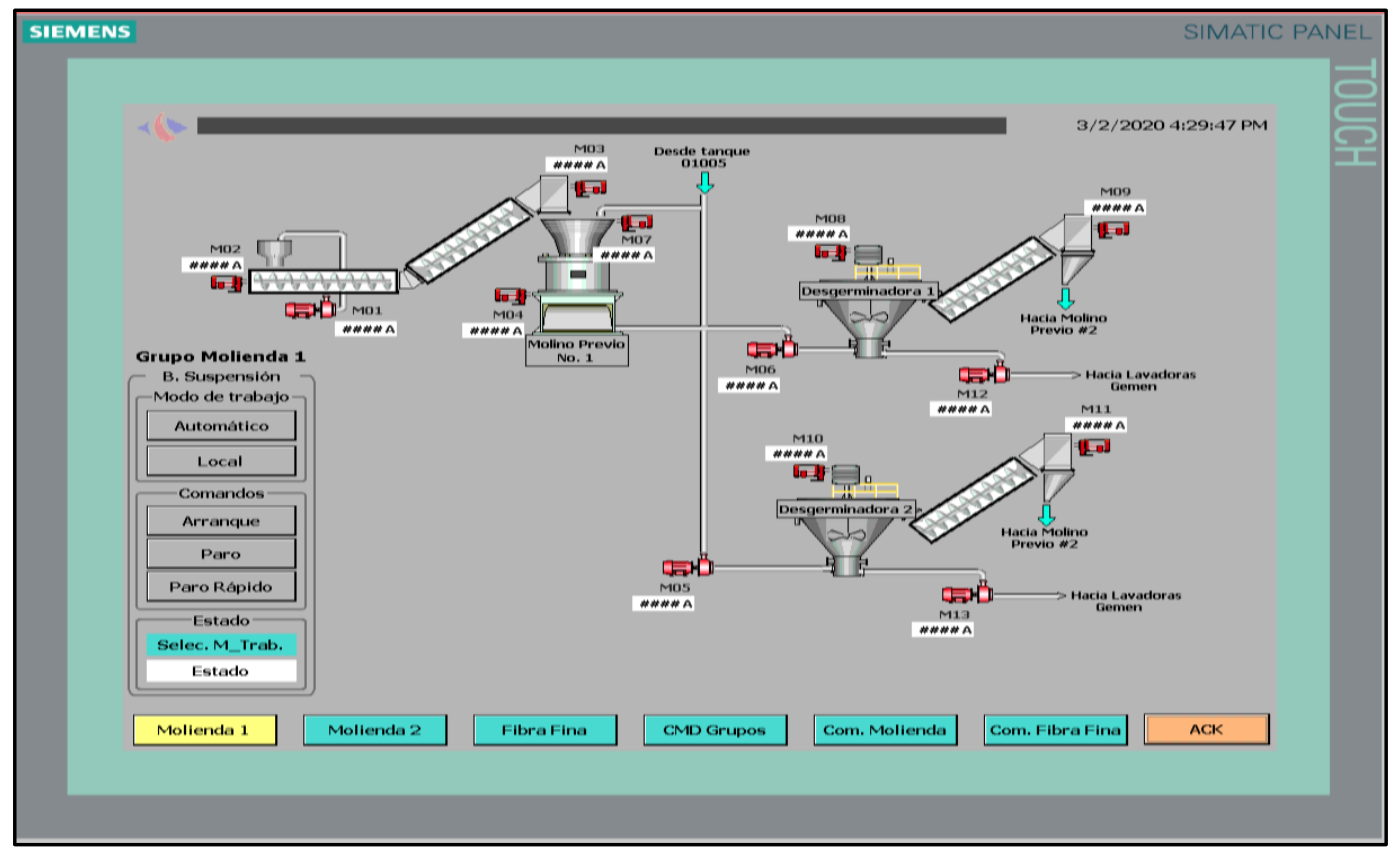

Figure 14: HMI based SCADA for wet milling process.

Source: Authors, (2020). 


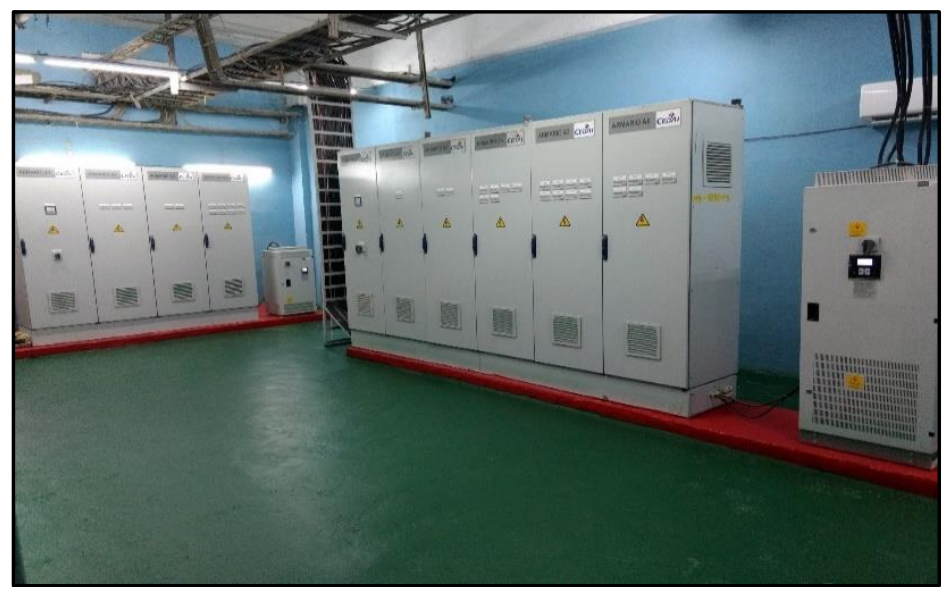

Figure 15: MCC room for wet milling process. Source: Authors, (2020).

Also, both implemented control systems, despite being different, brought a significant economic impact to production levels, product quality and efficiency. All these indicators were increased considerably and, according to the collected production data, the production levels augmented three times the initial value after executing the automation engineering service.

\section{CONCLUSIONS}

In this automation engineering service, control systems were meticulously developed and implemented, adjusted to the sequence operation of the processes, their control algorithms and operational needs, through modern technologies. All these actions contribute to the technological update of the factory.

With the implemented SCADAs, centralized monitoring and control of steeping and wet milling processes were achieved, facilitating processes operation through a friendly and easy-to-use environment.

The increased production levels obtained after the described automation engineering service was executed, establishes Automation as one of the most viable ways to optimize production processes.

\section{REFERENCES}

[1] AMS USDA, Technical Evaluation Report - Sulfurous Acid, p.p. 1-11, 2014.

[2] The Corn Refining Process. Available in: https://corn.org/wpcontent/uploads/2009/11/CornRefiningProcess.pdf, Accessed on: March $3^{\text {rd }}, 2020$.

[3] Corn Refiners Association. Corn Starch, 11th Edition, p.p. 710, 2006.

[4] The Basics of PLCs (Programmable Logic Controllers). Available in: https://electrical-engineering-portal.com/downloadcenter/books-and-guides/siemens-basics-of-energy/basics-of-plcs, Accessed on: March 3rd, 2020.

[5] W. Hernández, A. González, D. Darias, D. Gongora, G. García and R. O. Pacheco, Design of control systems for fermenters at the Molecular Immunology Center, ITEGAM - JETIA, Vol. 03, № 12, p.p. 12-19, 2017.

[6] What is an HMI? Available in: https://realpars.com/what-ishmi/\#, 2018, Accessed on: March $3^{\text {rd }}, 2020$.

[7] SIEMENS AG, Industrial Controls Motor management and control devices. SIMOCODE pro. System Manual, 2019.
[8] SIEMENS AG, Industrial Controls Soft starters and solid-state switching devices. 3RW44 soft starters. Manual, 2016.

[9] SIEMENS AG, SIMATIC S7-1200 Programmable controller. System Manual, V4.3.0, 2019.

[10] Static Var Compensation (SVC) Available in: https://new.abb.com/facts/static-var-compensation-(svc), 2020, Accessed on: March $3^{\text {rd }}, 2020$.

[11] CPU UN 216-2AD23-0XB0. Available in: http://www.unimat.com.cn/product/254.html, 2016, Accessed on: March $3^{\text {rd }}, 2020$.

[12] ASCON TECNOLOGIC, KR Controller and miniprogrammer. Engineering Manual, V1.0, p.p. 1-40.

[13] Alfa Laval, IndiTop. Mounting Instructions, p.p. 1-2, 2016.

[14] SIEMENS AG, Data sheet 6ES7214-1BG40-0XB0, p.p. 1-9, 2020. Available

in:

https://support.industry.siemens.com/cs/products/6ag1214-1bg402xb0/siplus-s7-1200-cpu-1214c-ac-dc-

rly?pid=566561\&mlfb=6AG1214-1BG40-

$2 \mathrm{XB} 0 \& \mathrm{mfn}=\mathrm{ps} \& \mathrm{lc}=\mathrm{en}-\mathrm{RU}$.

[15] CPU 1214C. Available in: https://www.plccity.com/shop/es/siemens-simatic-s7-1200-cpu-1214c/6es72141bg40-0xb0.html, 2016, Accessed on: March $3^{\text {rd }}, 2020$.

[16] SIEMENS AG, Data sheet 6ES7215-1BG40-0XB0, p.p. 1-9, 2020.

Available

in:

https://support.industry.siemens.com/cs/products/6es7215-1bg400xb0/cpu-1215c-ac-dc-rly-14di-10do-2ai-

2ao?pid $=126496 \& \mathrm{mlfb}=6 \mathrm{ES} 7215-1 \mathrm{BG} 40$ -

$0 X B 0 \& m f n=p s \& l c=e n-W W$.

[17] CPU 1215C. Available in: https://www.plccity.com/shop/es/siemens-simatic-s7-1200-cpu-1215c.html?p=2, 2016, Accessed on: March 3 ${ }^{\text {rd }}, 2020$.

[18] SIEMENS AG, Data sheet 6AV6647-0AG11-3AX0, p.p. 1-8, 2020. Available in: https://support.industry.siemens.com/cs/pd/104754?pdti=td\&dl=e n\&lc=en-IT.

[19] SIEMENS AG, SIMOCODE pro. Operating Instructions, p.p. $1-4,2014$.

[20] SIEMENS AG, SIRIUS Soft Starters 3RW44. System Manual, 2007.

[21] SIEMENS AG, SENTRON Power Monitoring Device SENTRON PAC3200. Manual, 2008.

[22] SIEMENS AG, SENTRON Power Monitoring Device PAC3100/PAC3200. Operating Instructions, p.p. 1-5, 2016.

[23] SIEMENS AG, SIMATIC S7-200 Programmable controller. System Manual, 2008.

[24] SIEMENS AG, SIMATIC HMI WinCC V7.0 System Description, 2008.

[25] SIEMENS AG, SIMATIC STEP 7 Professional V14. System Manual, 2016.

[26] SIEMENS AG, SIMOCODE ES V14 SP1 (TIA Portal). Available in: https://support.industry.siemens.com/cs/document/109745869/si mocode-es-v14-sp1-(tia-portal)?dti=0\&lc=en-AZ, 2017, Accessed on: March $3^{\text {rd }}, 2020$. 